\title{
Effect of Surface Conditioning Methods on Shear Bond Strength of Resin Luting Cement to All-ceramic Coping Material: An In Vitro Study
}

\author{
Pratik D Acharya ${ }^{1}$, Rupal J Shah ${ }^{2}$, Sejal A Mehta ${ }^{3}$, Dipak Solanki ${ }^{4}$
}

\begin{abstract}
Aim: To study the effect of various surface conditioning methods on shear bond strength of resin luting cement to all ceramic (zirconia) coping materials.

Materials and methods: Thirty-two caries-free human mandibular 3rd molars were embedded in acrylic blocks and 32 zirconia blocks of $5 \times 5 \times$ $5 \mathrm{~mm}$ dimension fabricated. Amongst them eight zirconia blocks were used without any surface treatment, eight were etched with $9 \%$ hydrofluoric acid, 8 were air abraded with 150 microns alumina sand particles, with rest eight both acid etching and air abrasion surface treatments were done. All zirconia blocks were luted with dual-cure resin cement to conditioned dentin surface of acrylic embedded mandibular $3 \mathrm{rd}$ molars. Shear bond strength of resin cement was evaluated with the help of instron universal testing machine.

Results: The mean shear bond strength of cemented air-abraded zirconia ceramics to dentine with dual-cure resin cement (ivoclair) exhibited the highest bond strength of $19.44 \mathrm{MPa}$ with a standard error of 1.13. The mean shear bond strength of zirconia ceramics with acid etched plus air abrasion surface treatment luted to dentine with dual-cure resin cement (ivoclair) exhibited bond strength of $13.20 \mathrm{MPa}$ with a standard error of 0.78 . The mean shear bond strength of zirconia ceramics with acid etched surface treatment, luted to dentine with dual-cure resin cement (ivoclair) exhibited bond strength of $10.91 \mathrm{MPa}$ with a standard error of 0.57 . The mean shear bond strength of zirconia ceramics without any surface treatment luted to dentine with dual-cure resin cement (ivoclair) exhibited bond strength of $10.49 \mathrm{MPa}$ with a standard error of 0.56 . Conclusion: Zirconia blocks with air abrasion shows the highest shear strength followed by acid etched plus air abrasion followed by only acid etching with $9 \%$ hydrofluoric acid.
\end{abstract}

Keywords: Luting cement, Prosthodontics, Surface conditioning methods.

International Journal of Prosthodontics and Restorative Dentistry (2019): 10.5005/jp-journals-10019-1226

\section{INTRODUCTION}

Rising requirement of esthetic restorations has increased the utilization of ceramics due to their enhanced esthetic as well as biocompatibility characteristic than metal-ceramics. However, the application of ceramic restorations has been restricted due to their comparatively decreased resistance to fracture. This led to the development of ceramic materials having appropriate mechanical characteristics such as thickly sintered zirconia ceramics and alumina. In disparity to usual feldspathic ceramic, the matrix pressure on the tetragonal particles of zirconium oxide is decreased due to the conversion of the tetragonal to a monoclinic phase under tensile stresses. This is connected with a localized volumetric raise of 3 to $5 \%$, consequential in compressive stresses, which neutralize the outer tensile stresses and may avoid cracks from spreading. ${ }^{2}$ These striking characteristics of zirconium oxide ceramics like more strength, good mechanical properties, ${ }^{3}$ and biocompatibility ${ }^{4}$ recommend an extensive clinical application such as fixed prostheses, post and core, implants, implant abutments, and resin-bonded fixed bridges.

The clinical application of zirconia-dental ceramics has multiple challenges when it compares to the bonding of these materials to dentine with cement. The structure and physical characteristics of these ceramics variance substantially from conventional feldspathic ceramic and need of another bonding method to accomplish a strong, long-time durable bond. ${ }^{5}$ The inside surface of these restorations has an exclusive roughness because of the making process. ${ }^{6}$ This micromechanical bonding may be affected by micro roughness. $^{7}$

\author{
1,2,4 Professor, ${ }^{3}$ Student \\ ${ }^{1-4}$ Department of Prosthodontics, Government Dental College and \\ Hospital, Ahmedabad, Gujarat, India
}

Corresponding Author: Sejal A Mehta, Student, Department of Prosthodontics, Government Dental College and Hospital, Ahmedabad, Gujarat, India, e-mail: drsejalmehta203@gmail.com

How to cite this article: Acharya PD, Shah RJ, Mehta SA, Solanki D. Effect of Surface Conditioning Methods on Shear Bond Strength of Resin Luting Cement to All-ceramic Coping Material: An In Vitro Study. Int J Prosthodont Restor Dent 2019;9(1):18-24.

Source of support: Nil

Conflict of interest: None

The previously reported studies indicated that enhanced bond strength to zirconia ceramic after air-abrasion. ${ }^{8}$ Furthermore, few studies concluded that air-abrasion might even strengthen zirconia ceramics. ${ }^{9}$ However, information on the retention of zirconia ceramics when luted with various cement and affection of airabrasion on its retention is limited in literature but Shahin, Kern et al. had done study on the impact of air-abrasion on the retention of zirconia ceramic crowns luted with various cement before and after non-natural aging. ${ }^{10}$

Most of the published studies indicated on the bonding properties of zirconia-dental ceramics have used cement blocks ${ }^{11}$ or stainless steel block ${ }^{12}$ as the bonding material. In contrasts to traditional clinical use when ceramic crowns or laminates are attached to enamel or dentine. The aim of the study was to evaluate the retention of zirconia ceramics cemented to dentine with the impact of air-abrasion and acid etching on its retention.

(o) The Author(s). 20190pen Access This article is distributed under the terms of the Creative Commons Attribution 4.0 International License (https://creativecommons. org/licenses/by-nc/4.0/), which permits unrestricted use, distribution, and non-commercial reproduction in any medium, provided you give appropriate credit to the original author(s) and the source, provide a link to the Creative Commons license, and indicate if changes were made. The Creative Commons Public Domain Dedication waiver (http://creativecommons.org/publicdomain/zero/1.0/) applies to the data made available in this article, unless otherwise stated. 


\section{Materials AND methods}

\section{Preparation of Teeth to Fabricate Specimens for the Study}

Thirty-two caries free, extracted and visually assessed fracture free, human third molars were preferred.

All the teeth were cleaned of debris by placing in $1 \%$ hydrogen peroxide solution and liquid sterilant such as $3 \%$ sodium hypochlorite solution. Calculus deposits and soft tissue were mechanically cleaned from teeth surfaces. The teeth were later preserved in distilled water at room temperature.

\section{Fabrication of Acrylic Resin Blocks}

A block of acrylic resin of dimensions $2.5 \mathrm{~cm} \times 1.5 \mathrm{~cm} \times 1.5 \mathrm{~cm}$ was fabricated. A putty index was made of the same. The selected teeth specimens were located in the center of the index, and the index was filled with auto polymerizing poly methyl methacrylate (PMMA) resin. Once polymerized the blocks were taken out of the putty index without damaging the index. Thirty-two resin samples were made by filling the index with the resin. Four different acrylic colors were used to differentiate between the various groups of specimens. Thus four color-coded groups were obtained with each group consisted of five specimens as mentioned below:

Group I (Yellow): Consisted of test specimens numbered 1-8 to which zirconia blocks (without surface treatment) luted with dual-cure resin cement.

Group II (Green): Consisted of test specimens numbered 9-16 to which zirconia blocks (acid etching surface treatment) luted with dual cure resin cement cement (Fig. 1).

Group III (Red): Consisted of test specimens numbered 170-24 to which zirconia blocks (air abrasion surface treatment) luted with dual cure resin c cement.

Group IV (Blue): Consisted of test specimens numbered 25-32 to which air-abraded plus acid etched zirconia blocks will be luted with dual-cure resin cement.

Each acrylic blocks was carefully trimmed on the lathe under continuous water irrigation till adequate dentine surface was exposed. All the specimens were evaluated to have a sufficient dentine surface on which square zirconia blocks of $5 \mathrm{~mm} \times 5 \mathrm{~mm}$ $x 5 \mathrm{~mm}$ could be bonded.

Each specimen was ended by grinding the specimen over $600-$ grit silicon-carbide paper $(\mathrm{SiC})$ of length $15 \mathrm{~cm}$ with 14 strokes for

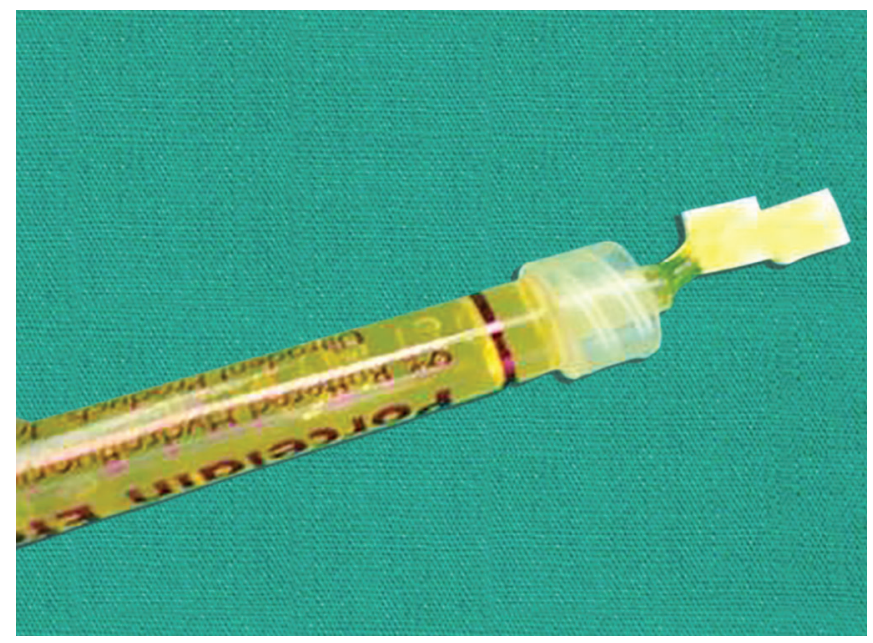

Fig. 1: Acid etching with $9 \%$ hydrofluoric acid each specimen under constant and continuous water irrigation, to produce standardized smear layers.

\section{Fabrication of Zirconia Specimens}

A standardized metal master specimen of $5 \mathrm{~mm} \times 5 \mathrm{~mm} \times 5 \mathrm{~mm}$ dimensions was prepared.

Computer-aided design and computer-aided manufacturing (CAD/CAM) (CAM $4 \mathrm{~K} 1$ milling machine) unit was used to mill thirty zirconia specimens (Diamond Klema Dental Product Gmbh Made In Australia White block-40 mm, partially sintered zirconia blocks) of same dimensions as that of the metal master specimen. All the specimens were later sintered (Furnace).

One surface of each specimen was selected for bonding. The selected surface of each specimen was ended with 600 -grit SiC of length $15 \mathrm{~cm}$ with 14 strokes under constant and continuous water irrigation. In 16 specimens, the selected surfaces were subsequently airborne-particle abraded with $50 \mu \mathrm{m}$ aluminum oxide for a maximum of 15 seconds under 4-5 bar pressure. Eight specimens were kept without any treatment and eight specimens were etched with $9 \%$ hydrofluoric acid. From 16 specimens which were air abraded amongst them, eight specimens were again acid etched.

\section{Cementation Procedure}

All the zirconia blocks were cemented on prepared dentine surface with dual-cure resin cement (ivoclair) (Fig. 2).

During cementation, zirconia blocks were seated initially with firm finger pressure followed by a uniform load of $5 \mathrm{~kg}$ using the jig. Excess cement was cleared from the margins. After thirty minutes all the specimens were preserved in the water at room temperature for 24 hours.

\section{Testing the Specimens}

All the specimens were tested for shear bond strength by using Universal Testing Machine with a cross-head speed of $1 \mathrm{~mm} / \mathrm{min}$ (Instron 33R 4467, Instron Limited, Buckinghamshire, England) (Fig.3). The resulting data of shear bond strength for all the 32 specimens were collected.

The data were analyzed by one way analysis of variance (ANOVA) intergroup comparison followed by nonparametric Kruskal-Wallis Mann-Whitney U test using SPSS version 22 software.

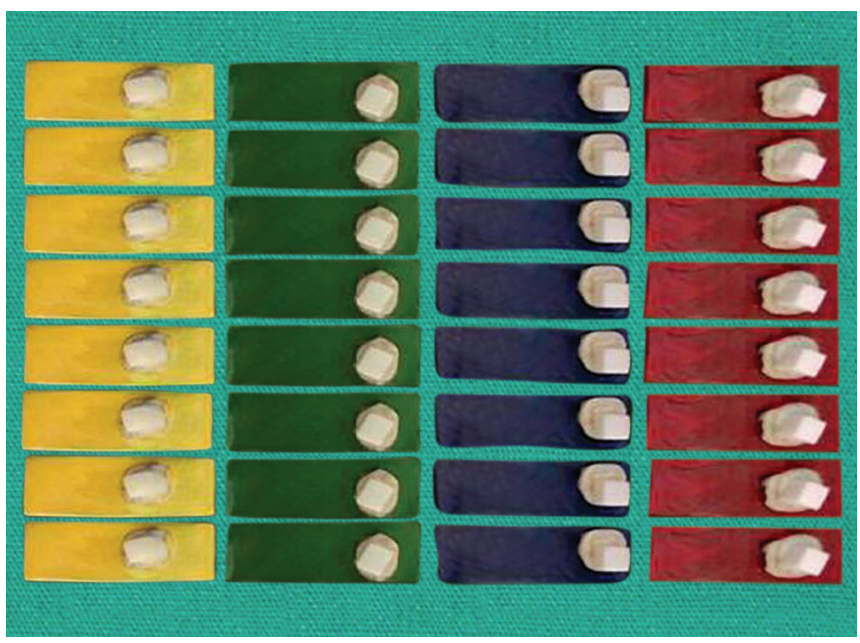

Fig. 2: Zirconia blocks cemented with resin cement to tooth with dual cure ivoclair resin cement after various surface treatment 


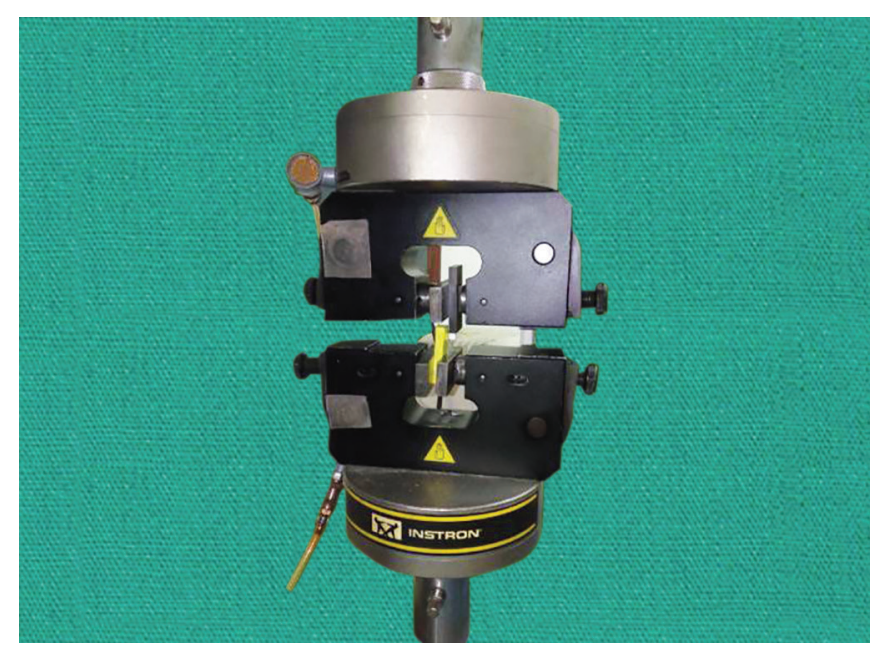

Fig. 3: Shear force is applied on specimen in universal testing machine

\section{Results}

The values for shear bond strength of resin cement to zirconia ceramics luted to dentine after various surface treatments were obtained and were subjected to statistical analysis.

Tables 1 to 4 show the shear bond strength of each specimen, described in their respected group's tables and graphs (Graphs 1 to 4). Table 5 shows descriptive data of all four study groups. Table 5 shows the mean shear strength of group 1 is $10.49 \pm 1.60$ and standard error of 0.568 (Graph 1), group 2 is $10.91 \pm 1.61$ and standard of 0.570 (Graph 2), group 3 is $19.44 \pm 3.20$ and standard error of 1.13 (Graph 3), group 4 is $13.20 \pm 2.22$ and standard error of 0.785 (Graph 4). These data are supported by previously reported studies. ${ }^{8}$

Table 1: Shear bond strength of specimens in group I

\begin{tabular}{ll}
\hline Specimen no. & Shear bond strength $(\mathrm{mpa})$ \\
\hline 1 & 9.765 \\
2 & 11.25 \\
3 & 10.22 \\
4 & 8.15 \\
5 & 13.12 \\
6 & 10.17 \\
7 & 12.11 \\
8 & 9.15 \\
\hline
\end{tabular}

Table 3: Shear bond strength of specimens in group III

\begin{tabular}{ll}
\hline Specimen no. & Shear bond strength $(\mathrm{mpa})$ \\
\hline 17 & 18.85 \\
18 & 22.15 \\
19 & 12.46 \\
20 & 19.25 \\
21 & 20.22 \\
22 & 23.22 \\
23 & 19.2 \\
24 & 20.22 \\
\hline
\end{tabular}

Table 6 shows overall shear strength comparison with one-way ANOVA and it shows statistically significant differences present in mean shear strength of various groups compared, with one way ANOVA sum of squares between groups is 409.389, $\mathrm{df}=3$, mean square is 136.46 , and $\mathrm{F}=26.74$ and significance is $<0.001$ (Graph 5).

Table 7 shows intergroup comparison of mean shear strength, using posthoc Fisher LSD test. There is statistically significant differences present between the mean shear strength of various groups compared. On comparison of group I with group II, there is no significant differences present between the shear strength $p$ value is 0.711 . Other comparisons showed statistically significant differences between each other because $p$ value for other group comparison shows less than

Table 2: Shear bond strength of specimens in group II

\begin{tabular}{ll}
\hline Specimen no. & Shear bond strength $(\mathrm{mpa})$ \\
\hline 9 & 9.761 \\
10 & 9.188 \\
11 & 12.46 \\
12 & 10.67 \\
13 & 11.55 \\
14 & 8.9 \\
15 & 13.54 \\
16 & 11.25 \\
\hline
\end{tabular}

Table 4: Shear bond strength of specimens in group IV

\begin{tabular}{ll}
\hline Specimen no. & Shear bond strength $(\mathrm{mpa})$ \\
\hline 25 & 9.761 \\
26 & 9.188 \\
27 & 12.46 \\
28 & 10.67 \\
29 & 11.55 \\
30 & 8.9 \\
Specimen 31 & 13.54 \\
Specimen 32 & 11.25 \\
\hline
\end{tabular}

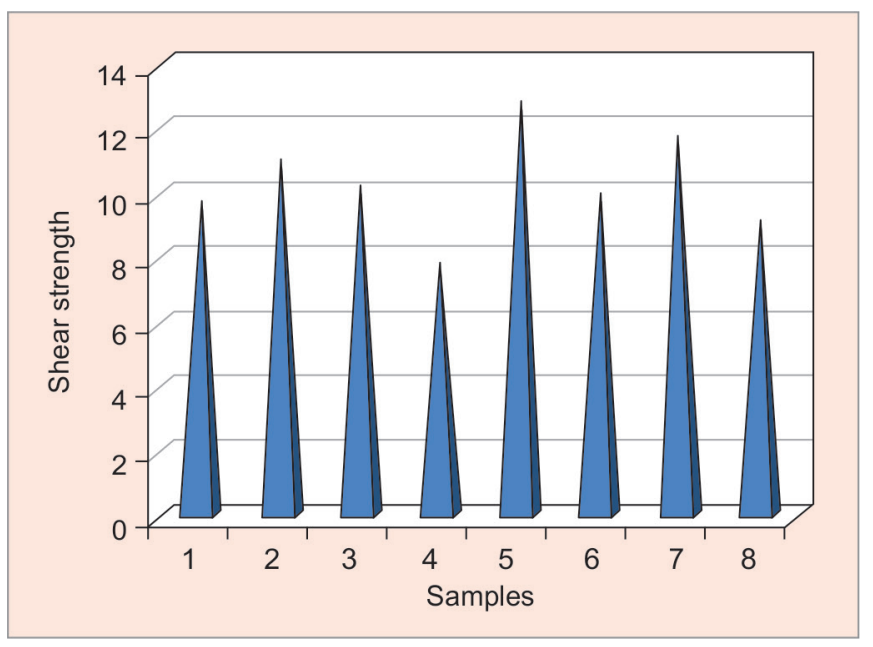

Graph 1: Shear strength of specimens of group I 


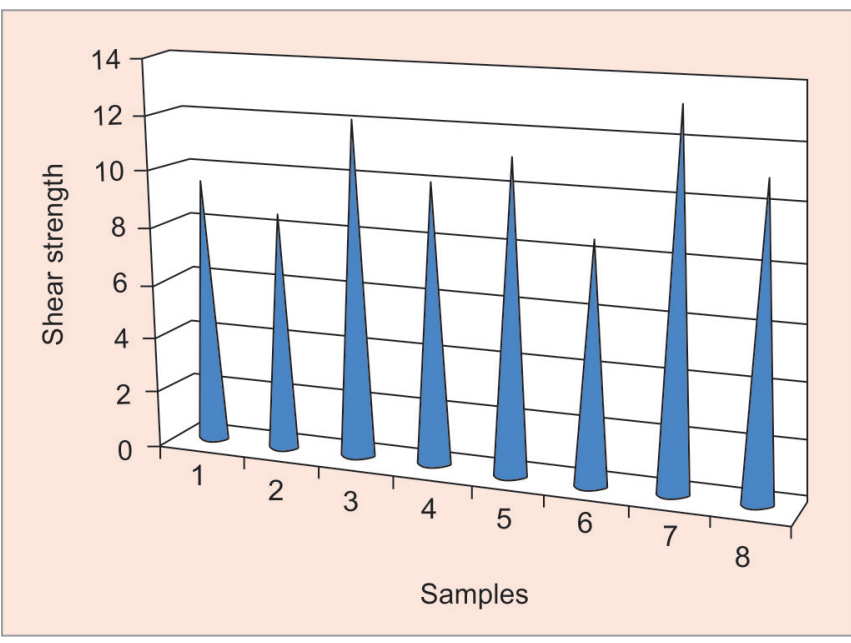

Graph 2: Shear strength of specimens of group II

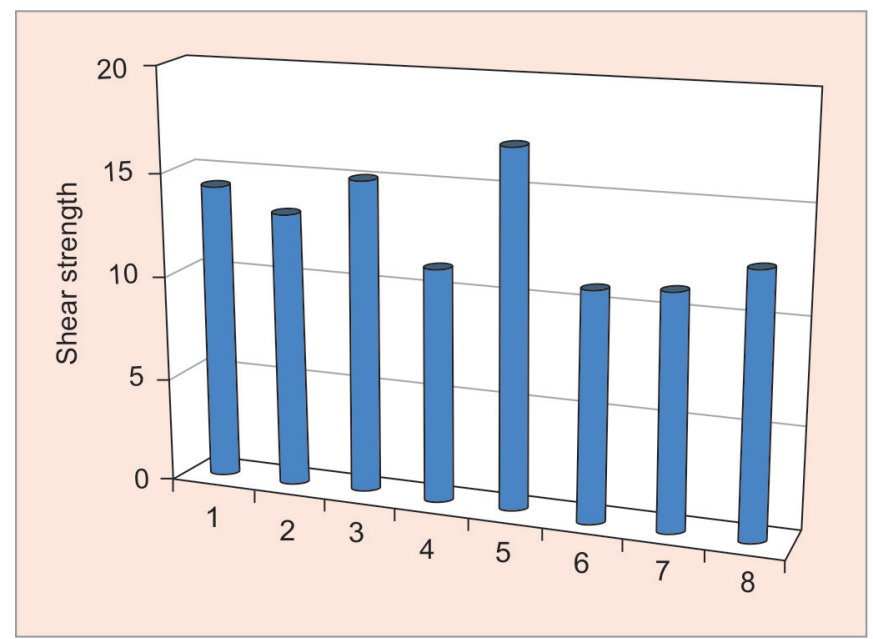

Graph 4: Shear strength of specimens of group IV

0.05. The lowest mean shear bond strength ( $\mathrm{mpa}$ ) was recorded in group I.

Table 8 shows comparison of mean ranks among the various groups compared (Graphs 6 and 7), Chi-square of all group is 18.82 which is significant $(<0.001)$. There are statistically significant differences present between the mean rank of various groups compared with the highest rank to group III and lowest

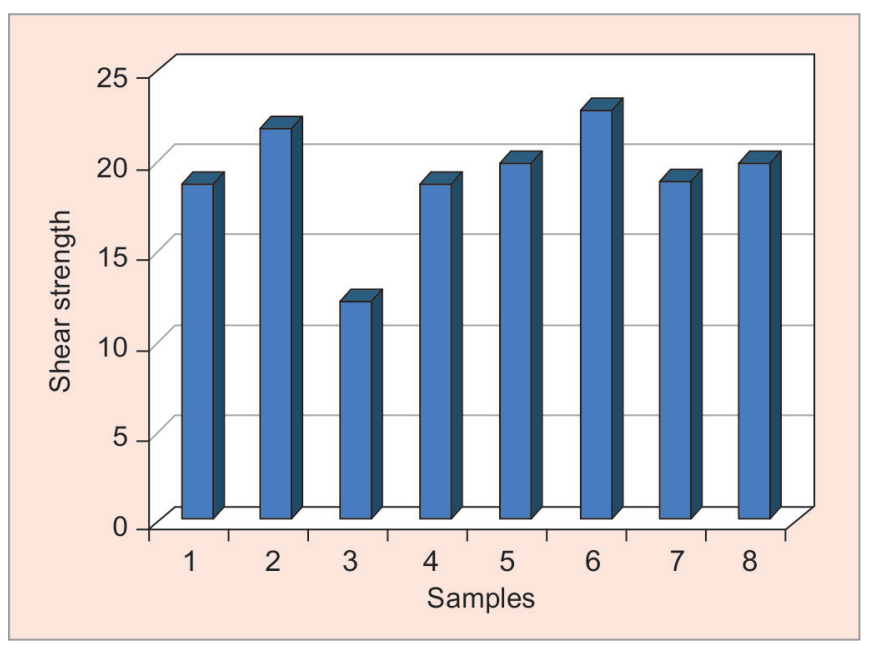

Graph 3: Shear strength of specimens of group III

to group I, which indicates the order of shear strength as follows. Group III > Group IV > Group II > Group I. These data support the study done by Shahin, Kern et al. ${ }^{10}$

Table 9 shows post hoc analysis-Mann-Whitney $U$ test in which $p$ value for groups $1-2$ is 0.65 which not significant, $p$ value for groups I-III is 0.001 which is significant, groups I-IV is 0.021 which is significant, groups II and III is 0.001 , groups II-IV is 0.049 which is significant, $p$ value for groups III-IV is 0.005 which is significant. We conclude from this table that surface treatment of zirconia improves shear strength with resin cement than without surface treatment. These data are supported by previously reported studies. ${ }^{13}$

\section{Discussion}

In current time, it has been considerable great interest for zirconium oxide (zirconia) ceramics, with a main influence in the prosthodontics. Because of its excellent mechanical characteristics, good biocompatibility, as well as optimized optical characteristics, zirconia has been considered as an alternative of metal-free restorations. "Transformation toughening" is an exclusive characteristic of Yttrium stabilized tetragonal zirconia polycrystals (Y-TZP), through which it can resist spreading of crack by converting to a monoclinic phase from a tetragonal. Altintas, Eldeniz et al. suggested that major clinical failures start from the cementation or intaglio surfaces of the restorations. ${ }^{14}$ So, the integrity of the cement to ceramic surfaces has a significant role in the longevity of the

Table 5: Descriptive data of various study groups

\begin{tabular}{|c|c|c|c|c|c|c|c|c|}
\hline & $N$ & Mean & $\begin{array}{l}\text { Std. } \\
\text { deviation }\end{array}$ & Std. error & $\begin{array}{l}\text { 95\% confidence } \\
\text { interval for mean }\end{array}$ & Minimum & Maximum & \\
\hline & & & & & Lower bound & $\begin{array}{l}\text { Upper } \\
\text { bound }\end{array}$ & & \\
\hline Group I & 8 & 10.49188 & 1.607616 & 0.568378 & 9.14787 & 11.83588 & 8.150 & 13.120 \\
\hline Group II & 8 & 10.91500 & 1.613652 & 0.570512 & 9.56595 & 12.26405 & 8.900 & 13.540 \\
\hline Group III & 8 & 19.44625 & 3.207384 & 1.133982 & 16.76481 & 22.12769 & 12.460 & 23.220 \\
\hline Group IV & 8 & 13.20750 & 2.221111 & 0.785281 & 11.35060 & 15.06440 & 10.850 & 17.120 \\
\hline Total & 32 & 13.51516 & 4.220729 & 0.746127 & 11.99342 & 15.03689 & 8.150 & 23.220 \\
\hline
\end{tabular}


Effect of Surface Conditioning Methods on Shear Bond Strength of Resin Luting Cement to All-ceramic Coping Material

Table 6: Over all shear strength comparison with one-way ANOVA

\begin{tabular}{llllll}
\hline \multicolumn{5}{c}{ ANOVA } \\
\hline & $\begin{array}{l}\text { Sum of } \\
\text { squares }\end{array}$ & Df & $\begin{array}{l}\text { Mean } \\
\text { square }\end{array}$ & $F$ & Sig. \\
\cline { 2 - 6 } $\begin{array}{l}\text { Between } \\
\text { groups }\end{array}$ & 409.389 & 3 & 136.463 & 26.746 & $<0.001$ \\
$\begin{array}{l}\text { Within } \\
\text { groups }\end{array}$ & 142.863 & 28 & 5.102 & & \\
Total & 552.251 & 31 & & & \\
\hline
\end{tabular}

bond. The failures starting from cementation surfaces recognized the requirement of a reliable luting mechanism to strengthen this critical area. A major limitation related to the utilization of zirconia is the trouble to bond this material to the prepared tooth surface. Zirconia fixed partial dentures (FPDs) and full-veneer crowns have been successfully utilized when luted with conventional cements like alumino-silicate cement. However, an adequate adherence to zirconia requires to be achieved when retention of the restoration depends mainly on adhesion, as in partial veneers and resin-bonded FPDs. $^{15}$

Various types of cements are utilized to lute crowns and bridges such as alumino-silicate, compomer, resin, zinc phosphate, and resin-modified glass-ionomer cements (RMGIC). Oilo and Jorgensen et al. revealed that the retentive feature of conventional cement principally depends on their physical strength and the micromechanical retention of the filler particles engaging the rough surfaces of the prepared tooth and restoration and not from an adhesiveness. It has been found that the application of routine cements for zirconia ceramic restorations and declared that a good amount of retention can be achieved with conventional cements. ${ }^{16}$ Ceramic manufacturers also state that zirconia can be cemented effectively with routine cements like alumino-silicate and zinc phosphate cement. ${ }^{13}$ Shahin, Kern et al. demonstrated significant failure rates regarding the loss of retention when utilizing glass-ionomer and zinc phosphate cement after sandblasting but sandblasting and resin cement gives better retenton. ${ }^{10}$

The bond of a luting agent to a ceramic surface is enhanced by various surface pretreatments. The standard protocol for ceramic adhesion incorporates etching of the ceramic surface with hydrofluoric acid and coating them with a bifunctional silane agent. The hydrofluoric acid attacks the glass phase and the silica network of the ceramic structure forming hexafluorosilicate. This method forms a microretentive surface with more free energy that enhances the association of the ceramic with luting agent. ${ }^{7}$ However, since

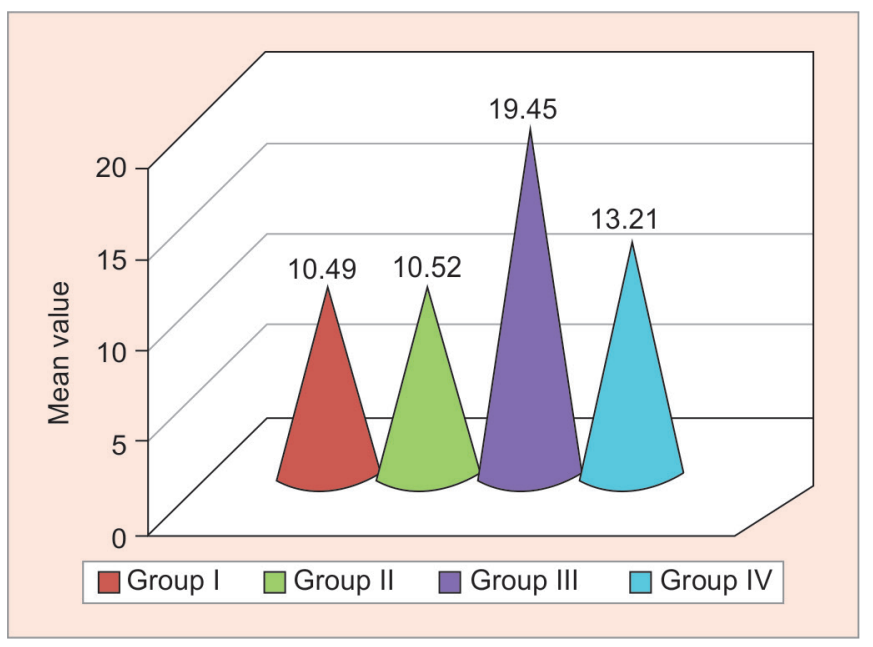

Graph 5: Mean value of shear strength of all groups

Y-TZP ceramic materials have a low proportion of glass phase and do not contain silicon dioxide, neither hydrofluoric acid etching nor silanization consequent in a good micromechanical bond between these materials and resin cements. ${ }^{17}$ Based on this, other surface treatments, such as airborne particle abrasion, tribochemical silica coating, Er: YAG laser irradiation, phosphate acidic monomers, functional silane monomers, and chemomechanical surface modifications have suggested achieving strong, reliable adhesion to Y-TZP ceramic materials. ${ }^{18}$

It has been reported that better adhesion strength to zirconia ceramic after air-abrasion. ${ }^{8}$ Nevertheless, the previously reported study does not recommend air-abrasion as they concluded it does not have a significant effect on the retention of zirconia. ${ }^{12}$ Hence, the question arises on the importance of air-abrasion and whether it should be eliminated when cementing crowns in order to avoid weakening of the ceramic.

Previously reported studies tested retention of the zirconia crowns, but both the studies have not tested retention with and without air-abrasion. ${ }^{19,20}$ The previous study investigated cementing resins containing adhesive cement, RMGIC and a self-adhesive modified composite resin for cementing air-abraded zirconia crowns to human teeth. However, they did not include zirconia crowns without air-abrasion. Another study utilized 12 various cement surface, modification groups. However, they did not utilize air-abrasion with alumina particles. ${ }^{20}$ The data on the influence of air-abrasion on retention of zirconia ceramic crowns, when cemented with conventional or adhesive luting cements is limited.

Table 7: Intergroup comparison of mean shear strength using posthoc Fisher LSD test

\begin{tabular}{|c|c|c|c|c|c|c|}
\hline Group & & $\begin{array}{l}\text { Mean difference } \\
(I-J)\end{array}$ & Std. error & $\begin{array}{l}\text { Sig. } \\
\text { p value }\end{array}$ & $\begin{array}{l}95 \% \text { confidence } \\
\text { interval }\end{array}$ & \\
\hline \multirow{3}{*}{ Group I } & & & & & Lower bound & Upper bound \\
\hline & Group II & -0.423125 & 1.129407 & 0.711 & -2.73661 & 1.89036 \\
\hline & Group III & $-8.954375^{*}$ & 1.129407 & 0.000 & -11.26786 & -6.64089 \\
\hline \multirow{3}{*}{ Group II } & Group IV & $-2.715625^{*}$ & 1.129407 & 0.023 & -5.02911 & -0.40214 \\
\hline & Group III & $-8.531250^{*}$ & 1.129407 & 0.000 & -10.84473 & -6.21777 \\
\hline & Group IV & $-2.292500^{*}$ & 1.129407 & 0.042 & -4.60598 & 0.02098 \\
\hline Group III & Group IV & $6.238750^{*}$ & 1.129407 & 0.000 & 3.92527 & 8.55223 \\
\hline
\end{tabular}

*The mean difference is significant at the 0.05 level 
Table 8: Comparison of mean ranks among the various groups compared

\begin{tabular}{lll}
\hline \multicolumn{3}{c}{ Ranks (Kruskal-Wallis) } \\
\hline Group & $N$ & Mean rank \\
\hline Group I & 8 & 9.31 \\
Group II & 8 & 11.00 \\
Group III & 8 & 27.56 \\
Group IV & 8 & 18.13 \\
Total & 32 & \\
Chi-square & 18.82 & Sig $-<0.001$ \\
\hline
\end{tabular}

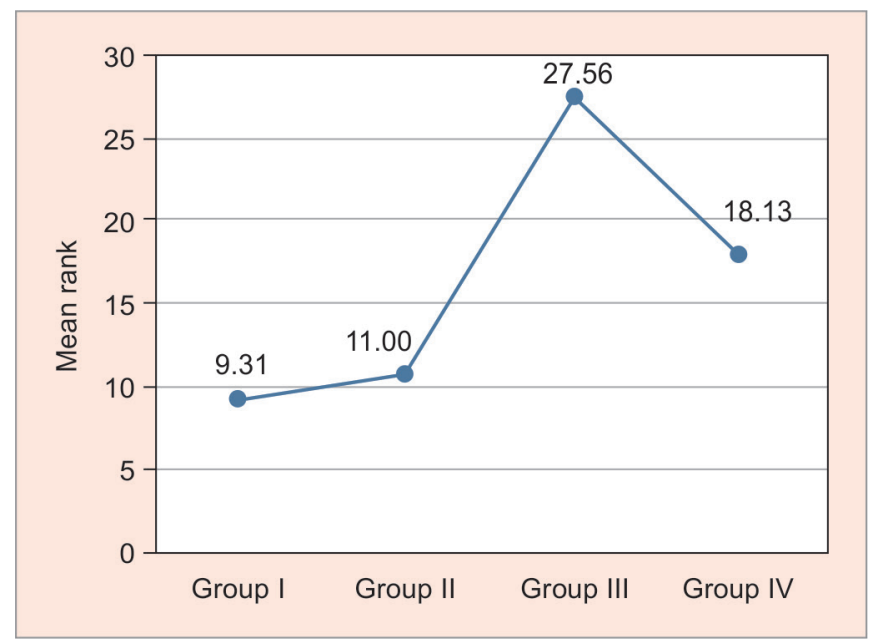

Graph 7: Comparison of mean shear strength in study groups

\section{ConCLUSION}

Within the limitations and based on the findings of this study, it was found that mean shear bond strength between air abraided zirconia and dentine was highest with dual-cure resin cement followed by acid etched plus air abraided which is followed by the only acid etched and without any surface treatment. Surface treatment of zirconia prosthesis must be luted to prepared tooth only after air abrasion.

\section{Clinical significance}

Various surface conditioning methods are introduced to improve the shear bond strength of resin luting cement to dentin with all ceramic coping materials. Within the limitation of this study and according to statistical analysis, it is observed that air abrasion surface conditioning methods are better than acid etched surface conditioning procedures in achieving shear bond strength of resin cement.

\section{References}

1. Christensen GJ. Why all-ceramic crowns? J Am Dent Assoc 1997;128:1453-1455.

2. Luthardt RG, Holzhuter M, Sandkuhl O, et al. Reliability and properties of ground Y-TZP-zirconia ceramics. J Dent Res 2002;81:487-14891.

3. Piconi C, Maccauro G. Zirconia as a ceramic biomaterial. Biomaterials 1999;20:1-225.

4. Luthardt RG, Sandkuhl O, Reitz B. Zirconia-TZP and aluminaadvanced technologies for the manufacturing of single crowns. Eur J Prosthodont Rest Dent 1999;7:113-119.

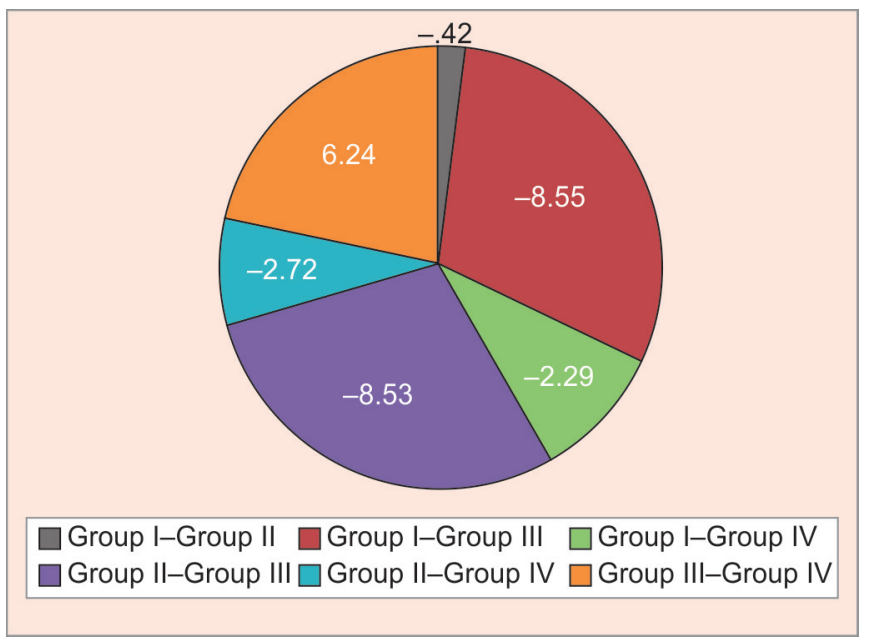

Graph 6: Mean difference in the shear strength among the groups compared

Table 9: Post hoc analysis-Mann-Whitney U test compared

\begin{tabular}{lll}
\hline Pair & pvalue & Interpretation \\
\hline Group I-Group II & 0.645 & Not significant \\
Group I-Group III & 0.001 & Significant \\
Group I-group IV & 0.021 & Significant \\
Group II-Group III & 0.001 & Significant \\
Group II-Group IV & 0.049 & Significant \\
Group III-Group IV & 0.005 & Significant \\
\hline
\end{tabular}

5. Seghi RR, Sorensen JA. Relative flexural strength of six new ceramic materials. Int J Prosthodont 1995;8:239-246.

6. Zeng K, Oden A, Rowcliffe D. Evaluation of mechanical properties of dental ceramic core materials in combination with porcelains. Int J Prosthodont 1998;11:183-189.

7. Blatz MB, Sadan A, Kern M. Resin ceramic bonding: a review of the literature. J Prosthet Dent 2003;89:268-274.

8. Blatz MB, Chiche G, Holst $\mathrm{S}$, et al. Influence of surface treatment and simulated aging on bond strengths of luting agents to zirconia. Quintessence Int 2007;38:745-753.

9. Kosmac T, Oblak C, Jevnikar $P$, et al. Strength and reliability of surface treated Y-TZP dental ceramics. J Biomed Mater Res 2000;53: 304-313.

10. Shahin R, Kern M. Effect of air-abrasion on the retention of zirconia ceramic crowns luted with different cements before and after artificial aging. Dent Mater 2010;26:922-928.

11. De Oyague RC, Monticelli F, Toledano M, et al. Influence of surface treatments and resin cement selection on bonding to denselysintered zirconium-oxide ceramic. Dent Mater 2009;25(2):172-179.

12. Luthy $\mathrm{H}$, Loeffel $\mathrm{O}$, Hammerle. CHF: Effect of thermocycling on bond strength of luting cements to zirconia ceramic. Dent Mater 2006;22:195-200.

13. Sailer I, Pjetursson BE, Zwahlen M, et al. Asystematic review of the survival and complication rates of all-ceramic and metal-ceramic reconstructions after an observation period of at least 3 years Part II: fixed dental prostheses. Clin Oral Implants Res 2007;18: 86-96.

14. Altintas S, Eldeniz AU, Usumez A. Shear bond strength of four resin cements used to lute ceramic core material to human dentin. J Prosthodont. 2008;17:634-640.

15. Oilo $G$, Jorgensen KD. The influence of surface roughness on the retentive ability of two dental luting cements. J Oral Rehabil 1978;5:377-389. 
16. Derand T, Molin M, Kleven E, et al. Bond strength of luting materials to ceramic crowns after different surface treatments. Eur J Prosthodont Restor Dent 2008;16:35-38.

17. Casucci A, Osorio $E$, Osorio R, et al. Influence of different surface treatments on surface zirconia frameworks. J Dent 2009;37:891897.

18. Miragaya L, Maia LC, Sabrosa CE, et al. Evaluation of self-adhesive resin cement bond strength to yttria-stabilized zirconia ceramic
(Y-TZP) using four surface treatments. J Adhes Dent. 2011;13: 473-480.

19. Palacios RP, Johnson GH, Phillips KM, et al. Retention of zirconium oxide ceramic crowns with three types of cement. J Prosthet Dent. 2006;96:104-114.

20. Ernst $C P$, Cohnen $U$, Stender $E$, et al. In vitro retentive strength of zirconium oxide ceramic crowns using different luting agents. J Prosthet Dent. 2005;93:551-558. 